\title{
Solidarity of generations in everyday life through the eyes of youth
}

\author{
L. G. Lebedeva ${ }^{1}$
}

${ }^{1}$ Samara State University of Economics, 141 Sovetskoi Armii Street, Samara 443090, Russian Federation

DOI: $10.18255 / 2412-6519-2020-1-54-65$

Research Article Full text in Russian

Solidarity refers not only to the socio-political sphere, but also to the sphere of intra-family relations. Solidarity and support of generations in everyday life is one of the natural traditions of inter-generational and intra-generational relationships. Solidarity is a structure of behavior inherited by individuals, fixed in the natural-historical process of succession of generations. The purpose of the article is to analyze the problems and trends in traditional relations of intra-family solidarity and mutual assistance of generations in everyday life. Sociological materials show that the modern young generation is, for the most part, completely or mostly independent in financial and economic terms. There is a noticeable trend that today's youth are noticeably less helpful in everyday life to older generations than older generations are helping young people. On the one hand, young people are largely separated from the parental family, become independent, less and less help parents in everyday life. On the other hand, a large part of parents finds themselves in a more difficult financial and economic situation and do not have real opportunities to help their children. It is necessary to recognize the paramount importance of the care of society and the state, especially in relation to two social groups - students and older people experiencing financial difficulties and in need of daily assistance. The manifestation of care on the part of society and the state, systematic targeted support for the most financially vulnerable groups of the population in its own way will support the modern meanings of traditional relations of solidarity and mutual assistance of generations in everyday life.

Keywords: solidarity; social solidarity; generations; parents; children; family help; youth

\section{INFORMATION ABOUT THE AUTHORS}

\author{
Lebedeva Ludmila G. $\quad$ E-mail: ludleb@mail.ru \\ Master of pedagogical Sciences, Senior Lecturer of the Department \\ of sociology and psychology
}

For citation: Lebedeva L. G. Solidarity of generations in everyday life through the eyes of youth // Social'nye i gumanitarnye znanija. 2029. Vol. 6, No 1. P. 54-65. (in Russ.) 


\title{
Солидарность поколений в повседневности глазами молодёжи
}

\author{
Л. Г. Лебедева ${ }^{1}$
}

${ }^{1}$ Самарский государственный экономический университет, ул. Советской Армии, 141, Самара, 443090, Российская Федерация

DOI: $10.18255 / 2412-6519-2020-1-54-65$

УДК 316.3/.4

Научная статья

Полный текст на русском языке

Солидарность относится не только к социально-политической сфере, но также и к сфере внутрисемейных взаимоотношений. Солидарность и поддержка поколений в повседневности является одной из естественных традиций межпоколенческих и внутрипоколенческих взаимоотношений. Солидарность является структурой поведения, наследуемой индивидуумами, закрепляемой в естественноисторическом процессе преемственности поколений. Целью статьи является анализ проблем и тенденций развития традиционных отношений внутрисемейной солидарности и взаимопомощи поколений в повседневной жизни. Социологические материалы показывают, что современное молодое поколение полностью или в основном независимо в финансово-экономическом плане. Существует тенденция, что сегодняшняя молодежь меньше помогает в повседневной жизни старшим поколениям, чем старшие поколения помогают молодежи. С одной стороны, молодые люди в значительной степени отделяются от родительской семьи, становятся самостоятельными, все меньше помогают родителям в повседневной жизни. С другой стороны, значительная часть родителей оказывается в более тяжелом финансово-экономическом положении и не имеет реальных возможностей помочь своим детям. Следует признать первостепенно важной заботу общества и государства прежде всего в отношении двух социальных групп: учащейся молодёжи, студентов и людей старшего возраста, испытывающих материальные трудности и нуждающихся в повседневной помощи. Проявление со стороны общества и государства заботы, систематической целевой поддержки наиболее уязвимых в материальном отношении групп населения по-своему поддержит современные смыслы традиционных отношений солидарности и взаимопомощи поколений в повседневной жизни.

Ключевые слова: солидарность; социальная солидарность; поколения; родители; дети; помощь в семье; молодёжь

ИНФОРМАЦИЯ ОБ АВТОРАХ

Лебедева Людмила Геннадьевна $\quad$ Email: ludleb@mail.ru

Старший преподаватель кафедры социологии и психологии

Для цитирования: Лебедева Л. Г. Солидарность поколений в повседневности глазами молодёжи // Социальные и гуманитарные знания. 2020. Том 6, № 1. С. 54-65.

(С) Лебедева Л. Г., 2020

This is an open access article under the CC BY-NC-ND license (http://creativecommons.org/licenses/by-nc-nd/4.0/) 


\section{Введение}

Солидарность (социальная солидарность) как понятие включает в себя, в частности, такие сущностные атрибуты (атрибутивные свойства), как взаимопомощь и поддержку, совместную ответственность; в основе солидарности - общность интересов индивидов и групп [1, с. 683-684].

Благодаря солидарности обеспечивается социальная интеграция («консенсус» по О. Конту). При этом в основе «консенсуса» лежат социальные чувства определённого типа - альтруистические чувства (противоположные эгоистическим чувствам, разъединяющим людей). В социологическом учении Огюста Конта семья выступает социальным институтом, которому присущ определённый «консенсус» [по: 2, с. 76-77].

Можно сказать, что «солидарность» и «консенсус» являются двумя сторонами одной «медали». На практике они проявляются в виде коллективизма (чему противоположен индивидуализм, основанный на эгоистических чувствах и интересах) проявляются в заботе о коллективных интересах и в коллективных действиях.

В то же время рост отчуждения, индивидуализма и взаимного равнодушия грозит социальной дезинтеграцией. На это обращают внимание учёные в разных странах.

Например, Роберт Д. Патнэм (Robert D. Putnam) в своей книге «Боулинг в одиночестве. Крах и возрождение американского сообщества» отметил, что функциональные сообщества разрушаются, потому что как церковь, так и семья потеряли силу и сплоченность [3, р. 303].

Зигмунд Бауман (английский учёный польского происхождения) проблеме индивидуализации и индивидуализированного общества посвятил специальную книгу «Индивидуализированное общество», где, в частности, подчеркнул, что «индивидуализация пришла надолго» [4, с. 63].

По оценке 3. Баумана, в индивидуализированном обществе как итоге процесса индивидуализации (а также одновременно и процесса глобализации) нация и семья перестали олицетворять вечно продолжающуюся длительность [Там же. С. 308]. В этих условиях для человека теряет значение устойчивость любых межличностных отношений, снижается значение семейных традиций и ценностей [Там же. С. 309], соответственно, разрушается преемственность поколений.

Для более глубокого понимания многих процессов в России определённое значение имеет изучение опыта Китая. Дело в том, что многое в российском обществе корнями уходит в советское (не такое уж давнее) прошлое («коммунистическое»), что так или иначе роднит его (российское общество) с китайским («коммунистическим») обществом. В этом отношении примечательно, что в Китае заметное место в общественной мысли занимают сегодня идеи «неофамилизма» и «индивидуализации по-китайски». При этом признаётся важность гармоничного сочетания самореализации личности и интересов семьи и непреходящая значимость межпоколенных связей в семье [5, с. 66].

Как показывают различные исследования, в сознании и поведении российской молодёжи всё более заметны проявления индивидуалистических ценностей [6, с. 124]. Речь ведётся и об ослаблении ценностей традиционной семьи.

Но так ли однозначно проявляют себя указанные тенденции применительно к повседневной жизни семьи, в особенности применительно к помощи младших и 
старших поколений друг другу? В частности, не вытесняют ли индивидуалистические ценности солидарность и поддержку поколений в повседневности?

Солидарность чаще рассматривается и анализируется в политическом аспекте (солидарность классовая, этно-национальная и т. п.). На самом деле это более широкое понятие, охватывающее и сферу внутрисемейных - внутрипоколенческих и межпоколенческих - взаимоотношений.

В отношении солидарности важно учитывать, что по-своему важны и макросоциальная солидарность, и микросоциальная солидарность (как два уровня социальной солидарности). Но при этом они не равнозначны: микросоциальная солидарность может существовать без солидарности на макроуровне, а макросоциальная солидарность не может существовать без солидарности на микроуровне (как целое не может существовать без согласования частей) [7, с. 7]. В то же время, когда в обществе представлены оба уровня социальной солидарности, то можно говорить о «непротиворечивости социальной солидарности», «о согласованной, или консистентной солидарности»; благодаря взаимодополнению и балансу обоих уровней социальной солидарности общество приобретает устойчивость и жизнеспособность [Там же. С. 8]. Данное положение можно считать одним из методологических обоснований важности изучения проблем солидарности и поддержки поколений в повседневности (на микроуровне).

Та или иная помощь родителям (бабушкам/дедушкам) или детям в повседневной жизни (работа по дому, приобретение продуктов и товаров для дома) является важной формой взаимодействия людей разных поколений, а вместе с этим и определённым показателем положительного, отрицательного или равнодушного отношения между ними.

Солидарность и поддержка поколений в повседневности являются одной из естественных традиций межпоколенческих и внутрипоколенческих взаимоотношений, «культурным кодом» (используя определение Клода-Леви Стросса [см.: 8, с. 495]). Солидарность является структурой поведения, наследуемой индивидуумами, закрепляемой и наследуемой в естественноисторическом процессе преемственности поколений, - определённой «культурной универсалией», по определению Маргарет Мид [9, с. 339-340].

По образному сравнению американского социолога Джеффри Александера, солидарность и поддержку поколений в повседневности можно также назвать «символическими элементами, которые находятся по сакральную сторону разделительной линии» [8, с. 349]. Вопрос, однако, в том, не уменьшается ли та часть отдельных людей, групп и общества в целом, которая остаётся именно на «сакральной» (традиционной) стороне от разделительной линии, в такой степени, что пропорция начинает «перевёртываться» в пользу каких-то других, модернистских или постмодернистских (нетрадиционных) ценностей в повседневности, далёких от ценностей солидарности и поддержки поколений?

В целом не отменяют ли (не замещают ли) индивидуалистические ценности солидарность поколений во внутрисемейных отношениях?

\section{Методы}

В какой мере существует помощь младших и старших поколений друг другу и насколько она взаимна? Для ответа на данный вопрос используем прежде всего данные двух социологических опросов: 
- «Молодежь Самарской области 2018» - опрос проведён под научным руководством В. Б. Звоновского, доктора социологических наук, президента 000 «Фонд социальных исследований» [10] в июне 2018 г. Опросом (интервью) было охвачено 1200 респондентов в возрасте от 14 до 60 лет, в том числе 600 респондентов в возрасте 14-30 лет. Часть материалов данного опроса отражена в монографии «Молодёжь. Смена поколений 2003-2018» [11].

- «"Отцы и дети": конфликт и сотрудничество, преемственность поколений 2018» - опрос организован и проведён под руководством Л. Г. Лебедевой в 2018 г. Анкетный опрос проводился в Самарской области. Опрошено 438 респондентов, представляющих разные поколенческие (возрастные) группы в возрасте от 18 лет и старше.

\section{Результаты}

Сравним социологические данные о помощи в повседневной жизни со стороны старших поколений младшим и, наоборот, со стороны младших поколений (детей) старшим поколениям - родителям (бабушкам/дедушкам).

Проблеме помощи разных поколений друг другу в опросе «Молодежь Самарской области 2018» были посвящены, в частности, вопросы:

- «Оказывают ли Вам родители помощь в повседневной жизни работой по дому, приобретением продуктов и товаров для дома. Если оказывают, то как часто?»;

- «Оказываете ли Вы помощь своим родителям (бабушкам/дедушкам) в повседневной жизни работой по дому, приготовлением пищи, приобретением продуктов и товаров для дома. Если оказываете, то как часто?».

В связи с поставленной проблемой проанализируем ответы респондентов младшей (14-30 лет) возрастно-поколенческой группы на два указанных вопроса (таблица 1).

Совпадают доли ответов «Помогаю(т) ежедневно или практически ежедневно» по вопросу «Оказывают ли Вам родители помощь ...?» $(39,4$ \%) и по вопросу «Оказываете ли Вы помощь своим родителям ...?» $(39,0$ \%).

И почти совпадают также доли ответов «Помогаю(т) не чаще раза в месяц» и «Помогаю(т) не чаще одного-двух раз в год», которые в сумме составляют 23,1 \% по вопросу «Оказывают ли Вам родители помощь ...?» и 26,6 \% по вопросу «Оказываете ли Вы помощь своим родителям ...?».

Такие совпадения по-своему показывают взаимный характер помощи родителей детям и детей родителям.

Но есть и определённые отличия в ответах на два противоположных по характеру вопроса.

Так, на вопрос «Оказывают ли Вам родители помощь ...?» более или менее регулярную помощь признали чуть менее половины $(49,6 \%)$ респондентов младшей возрастной группы, а на вопрос «Оказываете ли Вы помощь своим родителям ...?») положительно ответили почти две трети $(61,9 \%)$ респондентов этой же возрастной группы. 


\section{Распределение ответов на вопросы об оказании друг другу представителями разных поколений помощи в повседневной жизни, процент от числа респондентов (n) ${ }^{1}$}

\begin{tabular}{|c|c|c|c|c|}
\hline \multirow{3}{*}{ Ответ } & \multicolumn{2}{|c|}{$\begin{array}{c}\text { «Оказывают ли Вам } \\
\text { родители помощь ...?» }\end{array}$} & \multicolumn{2}{|c|}{$\begin{array}{c}\text { «Оказываете ли Вы помощь } \\
\text { своим родителям ...?» }\end{array}$} \\
\hline & \multicolumn{2}{|c|}{ 14-30 лет } & \multicolumn{2}{|c|}{ 14-30 лет } \\
\hline & \multicolumn{2}{|c|}{$n=600$} & \multicolumn{2}{|c|}{$n=600$} \\
\hline Не помогает(ют) & 25,3 & 25,3 & 9,1 & 9,1 \\
\hline $\begin{array}{l}\text { Помогаю(т) не чаще } \\
\text { одного-двух раз в год }\end{array}$ & 4,8 & \multirow{2}{*}{23,1} & 5,4 & \multirow{2}{*}{26,6} \\
\hline $\begin{array}{l}\text { Помогаю(т) не чаще раза в } \\
\text { месяц }\end{array}$ & 18,3 & & 21,2 & \\
\hline $\begin{array}{l}\text { Помогаю(т) не чаще раза в } \\
\text { неделю }\end{array}$ & 10,2 & \multirow{2}{*}{49,6} & 22,9 & \multirow{2}{*}{61,9} \\
\hline $\begin{array}{l}\text { Помогаю(т) ежедневно или } \\
\text { практически ежедневно }\end{array}$ & 39,4 & & 39,0 & \\
\hline Трудно сказать & 2,0 & 2,0 & 2,4 & 2,4 \\
\hline Итого & 100 & 100 & 100 & 100 \\
\hline
\end{tabular}

В то же время весьма заметная доля респондентов (25,3 \%) признала, что родители им «Не помогают». В свою очередь лишь 9,1 \% респондентов отметили, что они не помогают своим родителям в повседневной жизни.

Эти отличия можно объяснить двумя основными причинами. С одной стороны, молодёжь в значительной мере отрывается от родительской семьи, становится самостоятельной и всё меньше оказывает помощь родителям в повседневной жизни. С другой стороны, значительная часть родителей оказывается в более сложной материально-финансовой ситуации и не имеет реальных возможностей помогать своим детям.

Поскольку (см. таблицу 1) четвёртая часть (25,3 \%) в младшей возрастной группе отмечает отсутствие помощи в повседневной жизни со стороны родителей, а ещё почти четвёртая часть $(23,1 \%)$ получает помощь от родителей лишь изредка («не чаще одного-двух раз в год» или «не чаще раза в месяц»), то можно сделать вывод, что современное младшее поколение в значительной массе своей оказывается весьма самостоятельным в материальном отношении.

Но некоторая, тоже значительная, часть молодёжи (49,6 \%) всё-таки получает часто и регулярно, в том числе и ежедневно, помощь в повседневной жизни от родителей. С какими факторами в основном можно связать такую ситуацию?

Прежде всего, обратим внимание на влияние таких факторов, как получение образования молодёжью и материальный уровень жизни молодёжи.

Как влияет статус учащегося или студента на получение молодёжью помощи в повседневной жизни со стороны старших поколений? (таблица 2).

\footnotetext{
${ }^{1}$ Источник: материалы опроса «Молодежь Самарской области 2018».
} 
Таблица 2

Распределение ответов на вопрос: «Оказывают ли Вам родители помощь в повседневной жизни работой по дому, приобретении продуктов и товаров для дома. Если оказывают, то как часто?» - в зависимости от статуса учащегося, студента, процент от числа респондентов (n) ${ }^{1}$

\begin{tabular}{|c|c|c|c|}
\hline \multirow{3}{*}{ Ответ } & \multicolumn{3}{|c|}{ 14-30 лет, уровень получаемого образования } \\
\hline & $\begin{array}{c}\text { Учащийся } \\
\text { средней школы, } \\
\text { лицея, Пту }\end{array}$ & $\begin{array}{c}\text { Студент } \\
\text { колледжа, } \\
\text { техникума }\end{array}$ & Студент вуза \\
\hline & $n=38$ & $\mathrm{n}=40$ & $\mathrm{n}=50$ \\
\hline Не помогает(ют) & 2,6 & 2,5 & 7,9 \\
\hline $\begin{array}{l}\text { Помогаю(т) не чаще одного- } \\
\text { двух раз в год }\end{array}$ & 0,0 & 2,5 & 0,0 \\
\hline $\begin{array}{l}\text { Помогаю(т) не чаще раза } \\
\text { в месяц }\end{array}$ & 0,0 & 7,5 & 8,4 \\
\hline $\begin{array}{l}\text { Помогаю(т) не чаще раза } \\
\text { в неделю }\end{array}$ & 0,0 & 7,8 & 11,5 \\
\hline $\begin{array}{l}\text { Помогаю(т) ежедневно или } \\
\text { практически ежедневно }\end{array}$ & 97,4 & 79,7 & 70,2 \\
\hline Трудно сказать & 0,0 & 0,0 & 2,0 \\
\hline Итого & 100 & 100 & 100 \\
\hline
\end{tabular}

Помощь со стороны родителей (в повседневной жизни работой по дому, приобретением продуктов и товаров для дома) необходима большинству (более $70 \%$ ) детей, особенно студентов, в период их учёбы.

Получение помощи от родителей отмечают 97,4 \% респондентов - учащихся средней школы, лицея, ПТУ.

Доля получающих помощь со стороны родителей заметно меньше среди студентов колледжа, техникума $(79,7 \%)$ и студентов вуза $(70,2 \%)$. Но в целом речь идёт о подавляющем большинстве студентов.

Можно предполагать, что заметная часть студентов (20-30 \%) в той или иной степени подрабатывает и тем самым снижает общую необходимость в получении помощи от своих родителей (либо потому и подрабатывает, что не получает помощи от родителей). Именно об этом свидетельствуют многие другие исследования, опросы. Но и в этом случае речь, видимо, не идёт о полном отсутствии той или иной помощи от родителей - помощь оказывается не ежедневно, а «не чаще раза в неделю» или «не чаще раза в месяц».

Лишь примерно каждый двенадцатый $(7,9 \%)$ из студентов вуза не получает от родителей помощи в повседневной жизни работой по дому, приобретением продуктов и товаров для дома.

Как влияет материальный уровень жизни молодёжи на оказание с её стороны помощи в повседневной жизни представителям старших поколений? (таблица 3).

\footnotetext{
${ }^{1}$ Источник: материалы опроса «Молодежь Самарской области 2018».
} 
Распределение ответов на вопрос об оказании помощи своим родителям (бабушкам/дедушкам) в повседневной жизни по группам респондентов с разным материальным уровнем жизни, процент от числа респондентов (n) 1

\begin{tabular}{|c|c|c|c|c|c|c|}
\hline \multirow{3}{*}{ Ответ } & \multicolumn{6}{|c|}{$\begin{array}{c}\text { 14-30 лет, ответ на вопрос: «А в целом Вы живете сейчас } \\
\text { лучше, хуже или примерно так же, как и большинство } \\
\text { окружающих Вас людей?» }\end{array}$} \\
\hline & \multicolumn{2}{|c|}{ Хуже } & \multicolumn{2}{|c|}{ Примерно так же } & \multicolumn{2}{|c|}{ Лучше } \\
\hline & \multicolumn{2}{|c|}{$n=56$} & \multicolumn{2}{|c|}{$n=459$} & \multicolumn{2}{|c|}{$n=86$} \\
\hline Не помогает(ют) & 19,5 & \multirow[b]{2}{*}{24,6} & 9,5 & \multirow[b]{2}{*}{14,8} & 0,0 & \multirow[b]{2}{*}{6,3} \\
\hline $\begin{array}{l}\text { Помогаю(т) не чаще } \\
\text { одного-двух раз в год }\end{array}$ & 5,1 & & 5,3 & & 6,3 & \\
\hline $\begin{array}{l}\text { Помогаю(т) не чаще раза } \\
\text { в месяц }\end{array}$ & 19,8 & 19,8 & 20,4 & 20,4 & 26,0 & 26,0 \\
\hline $\begin{array}{l}\text { Помогаю(т) не чаще раза } \\
\text { в неделю }\end{array}$ & 19,9 & \multirow[b]{2}{*}{50,3} & 21,8 & \multirow[b]{2}{*}{62,3} & 31,1 & \multirow[b]{2}{*}{67,7} \\
\hline $\begin{array}{l}\text { Помогаю(т) ежедневно } \\
\text { или практически } \\
\text { ежедневно }\end{array}$ & 30,4 & & 40,5 & & 36,6 & \\
\hline Трудно сказать & 5,3 & 5,3 & 2,5 & 2,5 & 0,0 & 0,0 \\
\hline Итого & 100 & 100 & 100 & 100 & 100 & 100 \\
\hline
\end{tabular}

Те, у кого материальный уровень жизни выше (лучше, чем у большинства окружающих людей), помогают своим родителям (бабушкам/дедушкам) в повседневной жизни (работой по дому, приготовлением пищи, приобретением продуктов и товаров для дома) чаще, чем те, у кого материальный уровень жизни ниже (хуже, чем у большинства окружающих людей).

Так, доля тех, кто помогает часто и регулярно («ежедневно или практически ежедневно» и «не чаще раза в неделю»), составляет чуть более двух третей $(67,7$ \%) среди тех, у кого положение лучше, и чуть более половины $(50,3$ \%) среди тех, у кого положение хуже.

Одновременно доля тех, кто не помогает вообще или помогает не часто («не чаще одного-двух раз в год»), составляет одну шестнадцатую часть (6,3 \%) среди тех, у кого положение лучше, и около одной четверти $(24,6$ \%) среди тех, у кого положение хуже.

При этом у тех, чей материальный уровень жизни примерно такой же, как у большинства окружающих людей, показатели оказываются средними между крайними группами респондентов - живущими хуже или лучше, чем большинство окружающих людей.

Таким образом, наглядно прослеживается связь между тем, каков материальный уровень жизни респондентов (соответственно, каковы их материальные возможности), и тем, как часто и регулярно они оказывают помощь своим родителям (бабушкам/дедушкам) в повседневной жизни.

При этом следует учитывать и такой момент, что в случаях более благополучного материального положения всей семьи родители (бабушки/дедушки) могут

\footnotetext{
${ }^{1}$ Источник: материалы опроса «Молодежь Самарской области 2018».
} 
в меньшей степени нуждаться в помощи в повседневной жизни от своих ближайших родственников, имея в виду возможность получения помощи от сервисных организаций на платной основе. В подобных случаях, видимо, нельзя считать, что ближайшие родственники (прежде всего дети, внуки) отказываются помогать в повседневной жизни своим родителям, бабушкам/дедушкам; помощь может оказываться (при необходимости), но в других формах - через сервисные организации (благодаря наличию определённых материальных возможностей семьи).

В случаях более или менее благополучного материального положения всей семьи качество повседневной жизни может не пострадать, поскольку вместо помощи ближайших родственников может быть помощь от сервисных организаций со специализированными профессиональными компетенциями.

В случаях плохого материального положения семьи речь идёт, как правило, об ухудшении качества повседневной жизни родителей (бабушек/дедушек) из-за отсутствия помощи им (работой по дому, приготовлением пищи, приобретением продуктов и товаров для дома) от ближайших родственников. Семьям с плохим материальным положением необходимы повышенное внимание и активное участие социальных служб в решении проблем людей, нуждающихся в повседневной помощи.

В целом социологические данные позволяют говорить о том, что современная молодёжь (по признанию респондентов - представителей самой молодёжи) в заметной степени меньше оказывает помощь в повседневной жизни старшим поколениям, чем сама молодёжь получает со стороны старших поколений.

\section{Обсуждение}

В исследовании, представленном в статье И. В. Поповой, была подвергнута проверке гипотеза: «В силу ослабления потенциала социальной консолидации местное сообщество представляет собой расколотое социальное пространство. Состояние социальных сетей как на микро-, так и на макроуровне не позволяет надеяться на их трансформацию в гражданские инициативы. Разрушение социальной консолидации по перечисленным причинам является основанием системного кризиса социальной солидарности» [12, с. 243]. По оценке И. В. Поповой, данная гипотеза получила своё подтверждение в исследовании [Там же. С. 254]. Не оспаривая данные утверждения применительно к упомянутому исследованию в рамках его объекта и предмета, всё же следует сделать ряд комментариев.

Так, в исследовании задавался вопрос: «Как часто Вы ощущаете близость, единение, солидарность с перечисленными ниже группами людей, с теми, к которым вы себя причисляете?». По мнению исследователей, самый высокий уровень консолидации в группах по возрасту и по мировоззрению доказывает предположение о том, что «в основе социальной консолидации прежде всего лежит единая ценностная система, которая формируется в силу одинаковых условий социализации» [Там же. С. 251]. Лидерами стали ответы: «С людьми своего поколения, возраста», «С теми, кто разделяет ваши взгляды на жизнь», «С теми, кто за справедливость». [Там же. С. 252]. Но в числе 14 предложенных исследователями вариантов ответов не было дано таких, которые прямо связаны с солидарностью/консолидацией членов семьи и представителей старшего и младшего поколений. Поэтому нельзя признать сделанные выводы достаточно полными, «всеобъемлющими». Однако, несомненно, что эти выводы в достаточной мере можно применять к сфере социально-политических отношений в социуме. 
Зарубежные исследователи Рональд Инглхарт и Кристиан Вельцель, основываясь на анализе массива данных по 80 странам, делают вывод о том, что в современном обществе происходят масштабные культурные изменения, отражающие процесс межпоколенческого изменения ценностей, связанный с индустриализацией и формированием постиндустриального общества [13, с. 145].

Однако, по критическому замечанию И. Г. Кузнецова, происходящий «дрейф ценностей» - это процесс замещения не самих ценностей, а смыслов, сопряженных с одними и теми же ценностями [14, с. 48]. Это подтверждают и приводимые нами социологические данные. Подавляющее большинство респондентов в возрасте 14-30 лет проявляет склонность придерживаться традиционных правил солидарности и взаимопомощи поколений в повседневной жизни.

Однако формирование постиндустриального общества действительно оказывает влияние на утверждение новых смыслов, сопряжённых с прежними ценностями (в данном случае - с ценностями солидарности, взаимопомощи и поддержки в семье). Более того, определённые сложности и трудности в обществе (например, связанные с социальной трансформацией и экономическим кризисом) и новые социальные условия, связанные с особенностями мобильности и расселения современного населения, также оказывают своё влияние.

В частности, нельзя не заметить определённого отрицательного влияния фактора материального неблагополучия (материальных трудностей, ограниченных материальных возможностей заметной части семей), снижающего реальные возможности для практического оказания своим ближайшим родственникам помощи в повседневной жизни (работой по дому, приготовлением пищи, приобретением продуктов и товаров для дома).

О серьёзности материально-финансовых проблем для значительной доли россиян свидетельствуют ответы респондентов, представленные в таблице 4.

Таблица 4

Распределение лидирующих ответов на вопрос: «Как Вы думаете, в какой степени Вы, ваши друзья и вообще люди вашего поколения в жизни сталкиваются со следующими проблемами?», процент от числа респондентов (n) по возрастно-поколенческим группам ${ }^{1}$

\begin{tabular}{|l|c|c|c|c|c|c|}
\hline \multirow{2}{*}{ Варианты ответа (проблемы) } & \multicolumn{2}{|c|}{$14-30$ лет } & \multicolumn{2}{|c|}{$31-45$ лет } & \multicolumn{2}{|c|}{$46-60$ лет } \\
\cline { 2 - 7 } & \multicolumn{2}{|c|}{$\mathrm{n}=600$} & \multicolumn{2}{|c|}{$\mathrm{n}=300$} & \multicolumn{2}{c|}{$\mathrm{n}=300$} \\
\cline { 2 - 7 } & $\%$ & Место & $\%$ & Место & $\%$ & Место \\
\hline $\begin{array}{l}\text { Получение перспективной, } \\
\text { хорошо оплачиваемой работы }\end{array}$ & 64,7 & 1 & 64,0 & 1 & 50,7 & 2 \\
\hline $\begin{array}{l}\text { Ограниченные финансовые } \\
\text { возможности }\end{array}$ & 47,6 & 2 & 57,9 & 2 & 60,1 & 1 \\
\hline Получение любой работы & 24,9 & 4 & 29,2 & 4 & 26,5 & 3 \\
\hline $\begin{array}{l}\text { Отсутствие мест, где можно } \\
\text { интересно проводить досуг }\end{array}$ & 27,8 & 3 & 31,8 & 3 & 17,5 & 4 \\
\hline
\end{tabular}

\footnotetext{
${ }^{1}$ Источник: материалы опроса «Молодежь Самарской области 2018».
} 
То есть первостепенными проблемами для представителей всех возрастно-поколенческих групп в настоящий период являются «Получение перспективной, хорошо оплачиваемой работы» (а для кого-то и «Получение любой работы») и «Ограниченные финансовые возможности». При этом «Ограниченные финансовые возможности» могут быть связаны не только с небольшим доходом или низкой заработной платой, но и с недостаточными социальными пособиями, стипендиями.

Взаимная материальная поддержка членов семьи является одной из традиционных функций семьи. В то же время семья всё чаще становится нуклеарной, а члены семьи стремятся к большей самостоятельности и материальной независимости.

В какой мере важна поддержка со стороны родственников, по мнению респондентов? (таблица 5).

Таблица 5

\section{Распределение ответов на вопрос: «Какое утверждение ближе к Вашей жизненной ситуации?», процент от числа респондентов (n) ${ }^{1}$}

\begin{tabular}{|l|c|c|c|c|c|}
\hline \multirow{2}{*}{ Ответы } & \multirow{2}{*}{ Всего } & \multicolumn{4}{|c|}{ Группы по возрасту (числу лет) } \\
\cline { 3 - 6 } & & $18-29$ & $30-44$ & $45-49$ & $\begin{array}{c}50 \text { и } \\
\text { старше }\end{array}$ \\
\cline { 3 - 6 } & $\mathrm{N}=438$ & $\mathrm{n}=112$ & $\mathrm{n}=105$ & $\mathrm{n}=97$ & $\mathrm{n}=124$ \\
\hline $\begin{array}{l}\text { Могу сам(а) обеспечить себя } \\
\text { и не нуждаюсь в поддержке } \\
\text { со стороны родственников }\end{array}$ & 38,1 & 22,3 & 40,0 & 48,4 & 42,7 \\
\hline $\begin{array}{l}\text { Без поддержки со стороны } \\
\text { родственников мне не выжить }\end{array}$ & 22,8 & 37,5 & 13,3 & 18,6 & 21,0 \\
\hline $\begin{array}{l}\text { Помощь родственников нужна } \\
\text { лишь иногда и в небольшой } \\
\text { мере }\end{array}$ & 39,1 & 40,2 & 46,7 & 33,0 & 36,3 \\
\hline Итого & 100 & 100 & 100 & 100 & 100 \\
\hline
\end{tabular}

Ответы «Могу сам(а) обеспечить себя и не нуждаюсь в поддержке со стороны родственников» и «Помощь родственников нужна лишь иногда и в небольшой мере» получили по всей выборке практически одинаковые доли голосов (почти по 40 \%). Ответ «Без поддержки со стороны родственников мне не выжить» получил чуть более одной пятой части голосов $(22,8 \%)$.

Таким образом, общий баланс голосов респондентов склонился в пользу важности поддержки, помощи в той или иной мере со стороны родственников. При этом о наименьшей способности обеспечить себя и обойтись без поддержки со стороны родственников заявили представители самой младшей группы (22,3 \%). Среди представителей старших поколений таковых две пятых и более (от 40,0 \% до 48,4 \%). Но и в этих группах более половины признают важность поддержки, помощи со стороны родственников в той или иной мере.

В связи с приведёнными социологическими фактами следует признать первостепенно важной заботу общества и государства прежде всего в отношении двух социальных групп - учащейся молодёжи, студентов и людей старшего возраста, испытывающих материальные трудности и нуждающихся в повседневной помощи.

\footnotetext{
${ }^{1}$ Источник: материалы опроса «"Отцы и дети": конфликт и сотрудничество, преемственность поколений 2018».
} 
Проявление со стороны общества и государства заботы, систематической целевой поддержки наиболее уязвимых в материальном отношении групп населения посвоему поддержит современные смыслы традиционных правил и отношений солидарности и взаимопомощи поколений в повседневной жизни.

\section{Ссылки / References}

1. Энциклопедический социологический словарь / под общ. ред. Г. В. Осипова. М.: РАН ИСПИ, 1995. 939 с.

2. История теоретической социологии. Социология XIX века (Профессионализация социально-научного знания) / Ю. Н. Давыдов (рук.) и др. М.: ИЧП «Изд-во Магистр», 1998. 448 c.

3. Putnam R. D. Bowling Alone: The Collapse and Revival of American Community. New York: Simon \& Schuster, 2000.541 p.

4. Бауман 3. Индивидуализированное общество / пер. с англ. под ред. В. Л. Иноземцева. М.: Логос, 2005. 390 с.

5. Клупт М. А. Семья в России и Китае: между реформами и традицией // Социологические исследования. 2019. № 5. С. 65-75. DOI: 10.31857/S013216250004957-5

6. Лебедева Л. Г. «Смыслы жизни» в динамике преемственности поколений // Вестник Самарского муниципального института управления. 2018. № 2. С. 119-124.

7. Кармадонов О. А. Солидарность, интеграция, конъюнкция // Социологические исследования. 2015. № 2. С. 3-12.

8. Александер Дж. Смыслы социальной жизни: Культурсоциология / пер. с англ. Г. К. Ольховикова; под ред. Д. Ю. Куракина. М.: Изд. и консалтинговая группа «Праксис», 2013. $640 \mathrm{c}$.

9. Мид М. Культура и преемственность. Исследование конфликта между поколениями // Мид М. Культура и мир детства. М., 1983. С. 322-361.

10. Фонд социальных исследований (Самарский областной фонд социальных исследований): сайт. URL: http://socio-fond.com/; https://vk.com/socio_fond

11. Молодёжь. Смена поколений 2003-2018 гг. Результаты социологического мониторинга молодежи Самарской области / под науч. ред. В. Б. Звоновского. Самара, 2019. 170 с.

12. Попова И. В. Ослабление консолидационного потенциала социума как фактор системного кризиса социальной солидарности // Социальные и гуманитарные знания. 2018. Том 4. № 4. С. 242-254.

13. Инглхарт Р., Вельцель К. Модернизация, культурные изменения и демократия: последовательность человеческого развития. М.: Новое издательство, 2011. 464 с.

14. Кузнецов И. Г. Ценностные ориентиры и социально-политические установки россиян // Социологические исследования. 2017. № 1. С. 47-55. 